\title{
Assessment of impact of borehole heat exchanger design on heat extraction/rejection efficiency
}

\author{
V.F. Gornov ${ }^{1}$, N.V.Peskov ${ }^{1,2}$, G.P. Vasilyev ${ }^{1}$ and M.V. Kolesova ${ }^{1}$ \\ ${ }^{1}$ JSC «INSOLAR-INVEST», Bol'shaya Filevskaya str. 32-3, Moscow, 121433 Russia \\ ${ }^{2}$ Lomonosov Moscow State University, Leninskie Gory 1, str. 52, Moscow, 119991 Russia
}

\begin{abstract}
The article considers the impact of design of borehole heat exchanger (BHE) as one of the main elements of a geothermal heat pump system on its efficiency in the ground heat extraction/rejection. Four BHE modifications are considered: coaxial with metal and polyethylene outside tube as well as single and double U-shaped structures of polyethylene tubes. Numerical modeling resulted to data on the efficiency of these BHE modifications for rejection heat into ground (heat pump system in cooling mode), and ground heat extraction (heat pump system in heating mode). Numerical values were obtained and BHEs were ranked according to their efficiency in both operation modes. Besides, additional calculations were made for the most common modification - double U-shaped design - in the ground heat extraction mode for various tube sizes with various wall thicknesses.
\end{abstract}

\section{Introduction}

The problem of increasing the specific heat extraction/rejection of ground heat exchangers is currently one of the most important for the future development of geothermal heat pump systems. Many scientists around the world are looking for ways to improve the efficiency of ground heat exchangers. So, there are a number of articles focused on optimizing the existing modifications of ground heat exchangers. For example, article [1] deals with the effect of various grouting materials on BHE thermal efficiency. The article considers grouting solutions based on graphite and traditional bentonite. Article [2] considers possible applications of phase-change fluid, namely $\mathrm{CO}_{2}$, in Ushaped BHEs. Article [3] is focused on the impact of ground heat exchanger tube arrangement across BHE section on its thermal resistance, and the authors of the article [4] proposed improvement of the double U-shaped model wherein the coolant is supplied through three tubes, and is raised through one tube.

In addition, there is a considerable amount of research dedicated to developing new designs of BHE. Article [5] proposes the new BHE design that enhances heat transfer from the ground to the BHE coolant due to natural convection of intermediate coolant filling the BHE cavity instead of "conventional" heat-conducting material. Article [6] considers the new design of a metal ground heat exchanger in the form of an aluminum tube with external finning. Article [7] is also focused on developing new designs of ground heat exchangers, but in contrast to the previous study, the authors suggest to use the U-shaped heat exchanger with internally finned tubes.

The authors of this article have set themselves the task to compare efficiency of coaxial and U-shaped BHEs both for rejection of heat to the ground and for its extraction.

\section{Numerical Analysis}

\subsection{Considered physical model}

The two most commonly used modifications of BHEs are coaxial and U-shaped.

Coaxial BHEs represent a large diameter pipe, inside which a smaller diameter pipe is located so that the coolant supplied through the inside pipe is then introduced into the annular channel, raising there and exchanging heat with the surrounding ground through the wall of the larger (outside) tube. Coaxial BHEs can be made of both metal and polyethylene, where the inner tube is usually made of polyethylene as a material with a lower thermal conductivity in order to minimize the thermal interference of descending and ascending flows of coolant (thermal short circuit effect).

U-shaped models are mainly made of plastic tubes and used in two modifications - with one or two Ushaped loops within a single borehole.

In assessing the impact of the design features of BHEs on the rate of heat extraction/rejection efficiency, four BHE models presented in Figure 1 were analyzed: 
- Coaxial model, polyethylene external tube with an outside diameter of $160 \mathrm{~mm}$ and wall thickness of $9.5 \mathrm{~mm}$;

- Coaxial model, steel external tube with an outside diameter of $160 \mathrm{~mm}$ and wall thickness of $7 \mathrm{~mm}$;

- Single U-shaped model, polyethylene tube with an outside diameter of $32 \mathrm{~mm}$ and wall thickness of $3 \mathrm{~mm}$;

- Double U-shaped model, polyethylene tube with an outside diameter of $32 \mathrm{~mm}$ and wall thickness of $3 \mathrm{~mm}$.

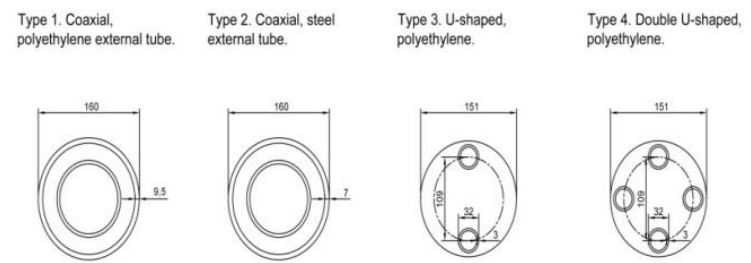

Figure 1. Analyzed BHE models

In modelling, all BHEs are placed in the same conditions, for this purpose data of geological surveys conducted in Martemianovo, Moscow region, were used as the ground design parameters. Data used in the calculations are shown in Table 1.

Table 1.

\begin{tabular}{|l|l|l|}
\hline $\begin{array}{l}\text { Ground } \\
\text { density, } \\
\mathrm{kg} / \mathrm{m}^{3}\end{array}$ & $\begin{array}{l}\text { Ground thermal } \\
\text { conductivity, } \\
\mathrm{W} /\left(\mathrm{m}^{\left.*{ }^{\circ} \mathrm{C}\right)}\right.\end{array}$ & $\begin{array}{l}\text { Ground volumetric } \\
\text { heat capacity, } \\
\mathrm{kJ} /\left(\mathrm{m}^{3} *^{\circ} \mathrm{C}\right)\end{array}$ \\
\hline 1766 & 1,71 & 2778 \\
\hline
\end{tabular}

The length of ground heat exchangers in the calculation is assumed to be $45 \mathrm{~m}$ at a drilling depth of $50 \mathrm{~m}$. It is their effective depth, minus the top part, where a distributor well and piping will be located.

\subsection{Modeling strategies}

Various models of BHE were placed in the same conditions to assess the specific heat extraction/rejection value. Thus it was assumed that outside surface of coaxial BHEs has a good contact with the surrounding ground, and in U-shaped models grouting material has the same thermal properties as the main ground. At the same time the effects of thermal short-circuit were not considered in order to simplify the calculations. Insignificance of these effects, for example, in coaxial models is shown in [8].

Numerical study to assess the impact of structural features of BHEs on the rate of specific heat extraction/rejection were conducted on following model. A horizontal circle at the depth $\boldsymbol{h}$ with center point in the center of a borehole is considered. Radius of the circle $\boldsymbol{R}$ is chosen to ensure that the ground temperature change on its border due to BHE operation is small enough to neglect it. In that flat region, formed by this big circle and small circles, representing cross-sections of BHE tubes, cut off from it, equation for thermal conductivity is considered:

$$
c \rho \frac{\partial T}{\partial t}=\lambda \Delta T
$$

As a boundary conditions zero heat flux at outer border and convective heat transfer at BHE tubes are taken. At initial moment ground is considered as undisturbed and having its natural temperature. Initial boundary value problem for equation (1) is solved by finite elements method. Internal temperature of coolant in BHE tubes is constant and depending on depth $\boldsymbol{h}$.

\subsection{Heat rejection}

Calculations were performed for ground temperature equal to $8^{\circ} \mathrm{C}$ and coolant temperature equal to $30^{\circ} \mathrm{C}$. The calculation was performed for the forecast period of 180 days. By this time the specific heat rejection value reaches a certain value, different from the initial one, that subsequently changes only slightly. The calculation results are shown in Fig. 2. "Minus" sign denotes heat is rejected into the ground.

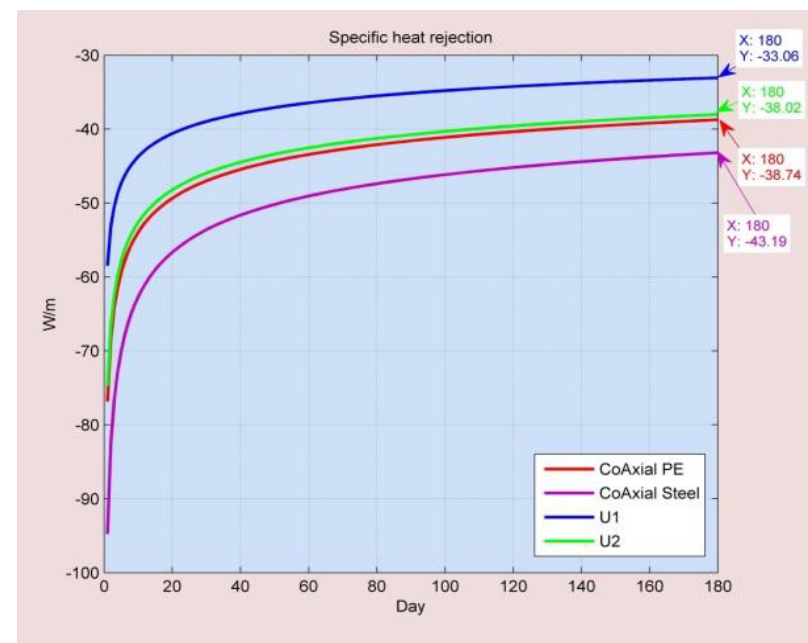

Figure 2. Time variation of the specific heat rejection.

The calculation results presented in the charts show that the specific heat rejection rate by 180 th day is distributed as follows:

1. Coaxial steel BHE $43.19 \mathrm{~W} / \mathrm{m}$;

2. Double U-shaped $38.74 \mathrm{~W} / \mathrm{m}$;

3. Coaxial polyethylene BHE $38.02 \mathrm{~W} / \mathrm{m}$;

4. Single U-shaped BHE $33.06 \mathrm{~W} / \mathrm{m}$.

These results show that in the mode of heat release into the ground, the considered BHE models have similar enough characteristics and the difference between the maximum and minimum values of the specific heat rejection is only $23.5 \%$. The use of the outside tube of heat conductive material (steel) in coaxial models as compared to the modification with polyethylene outside tube allows growth of the specific heat rejection of $13.6 \%$ and use of a double U-shaped model as compared with a 
single U-shaped model allows growth of $17.2 \%$ with almost doubled heat exchange surface.

\subsection{Heat extraction}

In order to compare the efficiency of heat extraction for the considered BHE models, the specific heat flow from the ground to the ground heat exchanger was estimated, and the input parameters were the same BHE geometric characteristics and ground parameters as for the previous calculation. BHE coolant temperature was assumed to be minus $8^{\circ} \mathrm{C}$.

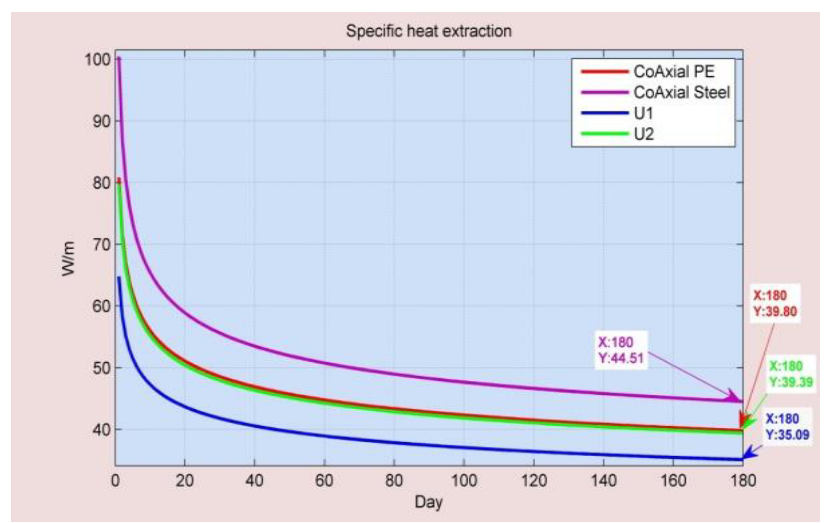

Figure 3. Time variation of the specific heat extraction.

The calculation results presented in the charts show that the specific heat extraction rate by 180 th day is distributed as follows:

1. Coaxial steel BHE $44.51 \mathrm{~W} / \mathrm{m}$;

2. Double U-shaped $39.80 \mathrm{~W} / \mathrm{m}$;

3. Coaxial polyethylene BHE $39,39 \mathrm{~W} / \mathrm{m}$;

4. Single U-shaped BHE $35,09 \mathrm{~W} / \mathrm{m}$.

These results also show that BHE design features play an important role in the heat extraction mode.

Comparing the results of this calculation with the calculation performed for the heat rejection mode it can be seen that BHE models are arranged in the effectiveness ranking in the same manner, and in this case variation is comparable and amounted to $21.2 \%$ ( $23.5 \%$ in heat rejection mode). Thus the use of outside tube made of heat-conducting material (steel) in coaxial models in comparison with the use of polyethylene outside tube allows to increase the specific heat extraction by $13 \%$ that is close to the same figure obtained for the heat release mode $(13.6 \%)$. The difference in the efficiency of use of double U-shaped structure as compared with a single U-shaped structure in this mode was almost $13.4 \%$ that is slightly less than in heat rejection mode $(17.2 \%)$.

\subsection{Effect of changes in geometric parameters of U-shaped BHEs on the heat extraction efficiency}

Additionally, the calculations of efficiency of dual Ushaped ground heat exchangers as the most common were conducted, with smaller wall thickness and larger tube diameter than in the already discussed modification. Thus, the following models of polyethylene tubes for a ground heat exchanger were chosen for calculations: $32 \times 2,40 \times 2$ and $40 \times 3$. The results of calculating the time variation of the specific heat flow for these models of ground heat exchangers are given in Figure 4 and in Table 2 .

\section{Specific heat extraction}

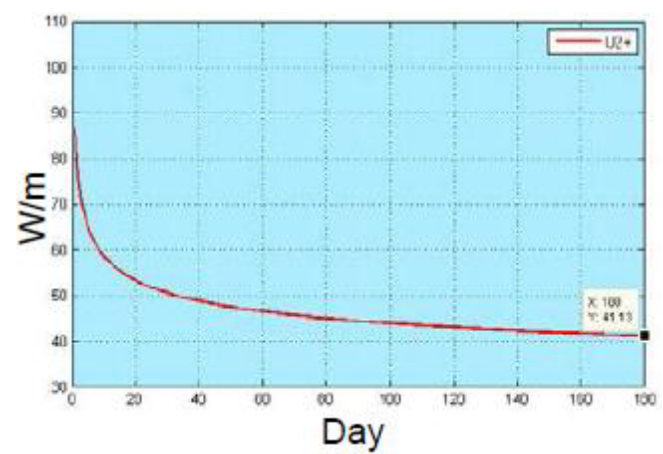

A)

Specific heat extraction

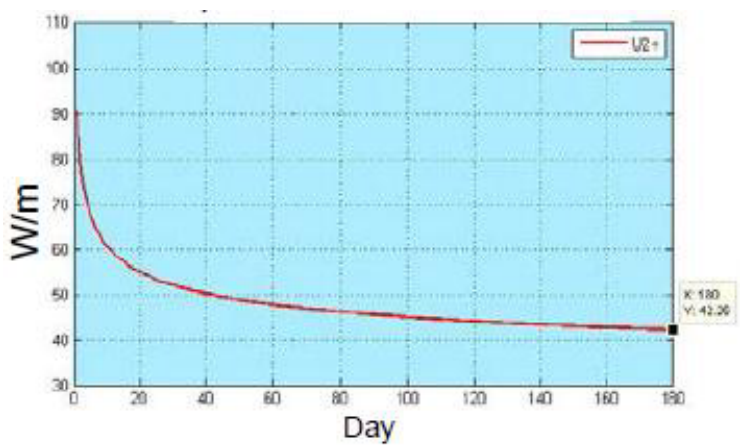

B)

Specific heat extraction

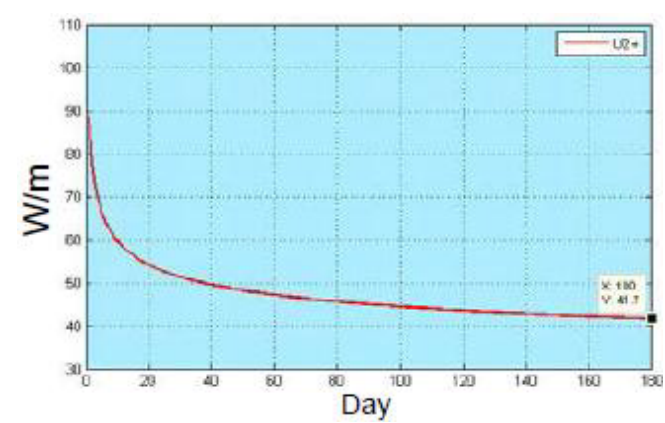

C)
A). Double U-shaped BHE 32x2;
B). Double U-shaped BHE 40x2;
C). Double U-shaped BHE 40x3.

Figure 4. Time variation of the specific heat extraction.

The calculation results show that change in the geometry of tubes constituting the ground heat exchanger affects the specific heat extraction, but this effect is relatively small. With increasing tube diameter with the 
same wall thickness, the specific heat recovery is predictably growing. In transition from diameter of 32 $\mathrm{mm}$ to $40 \mathrm{~mm}$, variation was $4.6 \%$ for tubes with a wall thickness of $3 \mathrm{~mm}$ and $2.7 \%$ for tubes with a wall thickness of $2 \mathrm{~mm}$. These data differ somewhat from the results obtained by authors of the study [9], where it was observed some reduction in efficiency of BHEs with 40 $\mathrm{mm}$ tube diameter compared to BHEs with $32 \mathrm{~mm}$ tube diameter. The explanation for this fact is that in the article [9] authors analyzed heat exchangers with tubes having a "standard wall thickness", and the thickness has not been specified. It is possible to assume that the "standard wall thickness" of $32 \mathrm{~mm}$ diameter tube was smaller than of $40 \mathrm{~mm}$ diameter tube that affected the final result. In our case, both tubes had the same wall thickness, so the results showed an increase in efficiency of BHEs with tube diameter increase.

Table 2.

\begin{tabular}{|c|c|}
\hline $\begin{array}{c}\text { Ground heat exchanger } \\
\text { tube dimensions, } \mathbf{m m}\end{array}$ & $\begin{array}{c}\text { Specific heat } \\
\text { extraction, } \mathbf{W} / \mathbf{m}\end{array}$ \\
\hline $32 \times 3$ & 39,9 \\
\hline $32 \times 2$ & 41,13 \\
\hline $40 \times 3$ & 41,7 \\
\hline $40 \times 2$ & 42,26 \\
\hline
\end{tabular}

In addition, the specific heat extraction growth is observed while reducing the wall thickness and keeping the outside diameter. For $40 \mathrm{~mm}$ diameter tubes, wall thickness reduction from 3 to $2 \mathrm{~mm}$ lead to the heat flow increase by $1.3 \%$, and for $32 \mathrm{~mm}$ diameter tubes - by $3.3 \%$.

\section{Discussion}

As a result of analysis, it was found that the impact of the BHE design on its efficiency varies from $20 \%$ to $25 \%$ depending on operation mode.

It is expected, that in heat rejection mode BHE efficiency would be significantly lower than in heat extraction mode, because these processes have different associated physical effects. Thus, in case of heat rejection into the ground, drying of the ground mass adjacent to the ground heat exchanger occurs with a corresponding reduction in its heat conductivity, which causes a sharp drop in thermal characteristics of ground heat exchangers. In this work we did not account for any effects of phase transitions of ground moisture, so instead of smaller influence of BHE design on its efficiency in heat rejection mode if compared to heat extraction mode we got it even bigger (23.5\% vs. $21.2 \%)$. It shows that models, not dealing with ground humidity and ground moisture phase transitions could lead to incorrect results in calculations and in final design of geothermal heat pump system. This conclusion is in good agreement with [10] where influence of groundwater on heat transfer efficiency.

In studying the effect of changes in geometric parameters of U-shaped ground heat exchangers on heat recovery efficiency, a relatively small impact of increase of outside diameter and reduction of wall thickness of tubes constituting the ground heat exchanger, on the parameters of the specific heat recovery has been shown. The reason is that by the end of heating season, when the temperature of the ground immediately adjacent to the ground heat exchanger has markedly decreased relative to its initial level, the efficiency of heat transfer is significantly affected not so much by heat conductivity of the material from which the heat exchanger is made, as heat conductivity of the ground itself.

\section{Conclusions}

The research presented in this article led to the following conclusions regarding the impact of BHE model on efficiency of the ground heat extraction and rejection:

a) BHE efficiency depends significantly on its construction, both in heat extraction and heat rejection modes.

b) Considered BHE models in both modes of operation in terms of efficiency can be ranked as follows (in decreasing order):

I. Coaxial model, steel external tube with $160 \mathrm{~mm}$ outside diameter;

II. Double U-shaped model, polyethylene tube with $32 \mathrm{~mm}$ outside diameter;

III. Coaxial model, polyethylene tube with $160 \mathrm{~mm}$ outside diameter;

IV. Single U-shaped model, polyethylene tube with $32 \mathrm{~mm}$ outside diameter.

c) The use of outside tube made of heat-conducting material (steel) in coaxial models in comparison with the use of polyethylene outside tube allows to increase the specific heat extraction by $13 \%$ that is relatively close to the value, obtained for heat rejection mode $(13.6 \%)$.

d) The difference in the efficiency of use of double Ushaped structure as compared with a single Ushaped structure in heat extraction mode was 13,4\% that is somewhat less than in heat rejection mode $(17.2 \%)$.

e) Efficiency of coaxial BHE with polyethylene external tube appeared to be very close to efficiency of double U-shaped BHE in both modes for chosen geometry and dimensions.

f) It is necessary to take into account the ground humidity and its change during the operation of ground heat exchangers, in process of calculations and characterization of ground heat exchangers, especially in the heat rejection mode.

g) The ability to control the humidity of ground adjacent to the ground heat exchanger can be a good tool to improve BHE efficiency, reduce their size and/or number, as well as to optimize the geothermal heat pump system as a whole.

\section{Acknowledgements}

The research was conducted by JSC "INSOLARINVEST" with the financial support of the Ministry of 
Education and Science of Russia. Unique identifier of the project RFMEFI57915X0115.

\section{References}

1. Selçuk Erol 1, Bertrand François. Efficiency of various grouting materials for borehole heat exchangers. Applied Thermal Engineering 70 (2014), 788-799.

2. Rita Mastrullo, Alfonso W Mauro, Laura Menna, Giuseppe P Vanoli. A model for a borehole heat exchanger working with $\mathrm{CO} 2$. 68th Conference of the Italian Thermal Machines Engineering Association, ATI2013. Energy Procedia 45 (2014), $635-644$.

3. S. Emad Dehkordi, Robert A. Schincariol, Stanley Reitsma. Thermal performance of a tight borehole heat exchanger. Renewable Energy 83 (2015), 698704.

4. Yong Liu, Yuqiao Zhang, Shengqiang Gong, Zhenfei Wang, Huiting Zhang. Analysis on the Performance of Ground Heat Exchangers in Ground Source Heat Pump Systems based on Heat Transfer Enhancements. Procedia Engineering 121 (2015) 19 $-26$.

5. S. Focaccia, F.Tinti.An innovative Borehole Heat Exchanger configuration with improved heat transfer. Geothermics 48 (2013), 93-100.
6. Ahmet Koyun, Hakan Demir, Zakir Torun. Experimental study of heat transfer of buried finned pipe for ground source heat pump applications International Communications in Heat and Mass Transfer 36 (2009), 739-743.

7. Benamar Bouhacina, Rachid Saim, Hakan F., Oztop, Numerical investigation of a novel tube design for the geothermal borehole heat exchanger. Applied Thermal Engineering 79 (2015), 153-162.

8. E. Zanchini, S. Lazzari, A. Priarone. Effects of flow direction and thermal short-circuiting on the performance of small coaxial ground heat exchangers. Renewable Energy 35 1255-1265 (2010).

9. Yang Li, Qingsong An, Liangxu Liu, Jun Zhao. Thermal performance investigation of borehole heat exchanger with different U-tube diameter and borehole parameters. Energy Procedia 61 (2014) $2690-2694$.

10. Jin Luo, Joachim Rohn, Wei Xiang, Manfred Bayer, Anna Priess. Experimental investigation of a borehole field by enhanced geothermal response test and numerical analysis of performance of the borehole heat exchangers, Energy 84 (2015), 473 484 